\title{
SOCIAL COSTS OF LOSS IN PRODUCTIVITY-RELATED ABSENTEEISM IN POLAND
}

\section{AGNIESZKA GENOWSKA ${ }^{1}$, JUSTYNA FRYC ${ }^{2}$, JAROSŁAW PINKAS ${ }^{3}$, JACEK JAMIOŁKOWSKI ${ }^{1}$, KRYSTYNA SZAFRANIEC ${ }^{4}$, ANDRZEJ SZPAK ${ }^{5}$, and IWONA BOJAR ${ }^{6}$}

${ }^{1}$ Medical University of Bialystok, Białystok, Poland

Faculty of Health Sciences, Department of Public Health

${ }^{2}$ Medical University of Bialystok, Białystok, Poland

Faculty of Medicine, Department of Rheumatology and Internal Medicine

${ }^{3}$ Centre of Postgraduate Medical Education, Warszawa, Poland

School of Public Health, Department of Healthcare Organizations and Medical Certification

${ }^{4}$ Jagiellonian University Medical College, Kraków, Poland

Faculty of Health Sciences, Department of of Epidemiology and Population Studies

${ }^{5}$ Institute of Rural Health, Lublin, Poland

Department of Epidemiology, Demography and Biostatistics

${ }^{6}$ Institute of Rural Health, Lublin, Poland

Department of Women's Health

\begin{abstract}
Objectives: The aim of this study was to estimate indirect costs associated with losses in productivity due to sickness absence among registered workers in Poland. Material and Methods: Data on sick leave durations in 2013 was obtained from the Social Insurance Institution (SII) (Zakład Ubezpieczeń Społecznych - ZUS). Based on the number of assumptions, this data was used for calculating absence durations. The costs of lost productivity were estimated on the basis of the measure of gross value added. Results: Estimated losses in productivity due to absenteeism in 2013 together accounted for $4.33 \%$ of gross domestic product (GDP) (17.09 billion euro). In the female population, the total value of losses amounted to 9.66 billion euro, but excluding the costs of pregnancy, childbirth, and puerperium ( 2.96 billion euro), it was 6.7 billion euro. In the male population, the loss amounted to 7.43 billion euro. The highest overall costs of sickness absence based on age were found in the age group of 30-39 years (5.14 billion euro, including pregnancy, childbirth, and puerperium - 1.474 billion euro; respiratory diseases -0.632 billion euro, injuries and poisonings -0.62 billion euro). In the group of people aged $>40$ years, the highest cost was generated by bone-muscular diseases (1.553 billion euro) and injuries and poisoning (1.251 billion euro). Higher losses in the productivity of women in addition to pregnancy, childbirth, and puerperium were due to mental and behavioral disorders ( 0.71 billion euro), diseases of the genitourinary system ( 0.38 billion euro), and neoplasms ( 0.35 billion euro). At the same time, in men, compared to women, we observed higher losses due to injuries and poisoning (1.65 billion euro), and diseases of musculoskeletal ( 1.26 billion euro), nervous ( 0.79 billion euro), circulatory ( 0.65 billion euro), and digestive ( 0.41 billion euro) systems. Conclusions: Improvement and further development of effective strategies for prevention of complications of pregnancy and chronic diseases in the workplace are necessary. Policies aimed at reduction of sickness absence could potentially increase prosperity and the socioeconomic situation in Poland. Int J Occup Med Environ Health 2017;30(6):917-932
\end{abstract}

Key words:

Sickness absence, Indirect costs, Productivity loss, Occupational medicine, Working age, Inequalities in health

Received: September 7, 2016. Accepted: November 16, 2016.

Corresponding author: A. Genowska, Medical University of Bialystok, Faculty of Health Sciences, Department of Public Health, Szpitalna 37, 15-295 Białystok, Poland (e-mail: agnieszka.genowska@umb.edu.pl). 


\section{INTRODUCTION}

Sickness absence is an important economic problem and is usually considered as a measure of a society's health determining occurrence of longstanding physical illness, disability, and mortality [1,2]. Sick leave refers to the total exclusion of workers from the labor process and is associated with loss of productivity. Under Polish law, the basis of an employee absenteeism is being exempt due to a worker's own sickness, illness of a child up to 14 years of age, or caring for a sick family member, if he/she remains in the same household with the insured during the period of care. Paid sick leave in the case of incapacity to work due to illness may last up to 182 days, and during pregnancy or in the course of tuberculosis to 270 days [3].

Absence from work due to illness is a complex phenomenon, which in a high percentage of cases is determined by the type of work and working conditions. Psychosocial environment of work plays one of the most important roles in the overall structure of the reasons for absence from work. Level of stress, style of management, quantitative and qualitative requirements of an employer, family responsibilities as well as time pressure have an impact on the well-being of an employee and his or her attitude towards professional duties. Health of a working population is also determined by factors such as lifestyle, environment, housing or the quality and availability of health care [4-7].

The data published by the European Foundation for the Improvement of Living and Working Conditions (Eurofound) emphasizes that Poland is among the countries with the highest average number of days of sickness absence in Europe [8]. Compared to other European countries, work-related health problems, including back pain, muscle stress and fatigue, are frequently reported by Polish workers [9]. It has been observed, however, that $30 \%$ of workers work for $>40 \mathrm{~h} /$ week and $60 \%$ of them work at the weekend, and a sense of job insecurity affects $24 \%$ of the workforce. In addition, exposure to the physical factors (e.g., chemicals - 21\%, smoke, fumes, powder, or dust $-20 \%$, noise $-35 \%$ and vibration $-27 \%$ ) in the working environment adversely affects physical condition of workers. Such a situation, as of May 2004, has been found to be more common in Poland than in other European Union countries [10]. Working hours, job insecurity and poorer conditions of working environment in Poland may lead to long-term health effects.

Poorer health status of the workforce and the related sickness absences generate high socioeconomic costs. The burden of disease in the working population may be reflected in terms of direct costs and indirect costs. Direct costs are associated with medical care, treatment of the diseases and their complications, as well as related non-medical activities (e.g., transport, administration and research). Indirect costs, on the other hand, are expressed as loss of productivity by a patient or a caregiver of the sick [11]. In the case of chronic diseases, indirect costs exceed direct costs, regardless of the methodology used for estimating these costs [12-14].

One of the methods for estimating indirect costs is the human capital approach (HCA), evaluating the loss of production from the perspective of society [15]. Indirect cost determined on the basis of HCA includes loss of production due to decreased productivity despite workers being present at work (presenteeism) and sickness absence of the workers (absenteeism) [11]. Indirect costs have become an integral part of the economic analysis of incapacity to work, which is a subject of continuous discussions. Existing methods used for measuring the cost of lost productivity differ [16-18]. The problem in estimating the costs of productivity is presenteeism and performance assessment of knowledge-based occupations [19]. Standardized methods to compare indirect costs of illness are lacking and, therefore, ongoing research focuses on finding an ideal tool for comparing indirect costs of illness [20,21]. 
The European Foundation for the Improvement of Living and Working Conditions draws attention to the fact that different methods are used nationally to analyze the cost of absenteeism. In addition, some countries do not engage in such an analysis, which involves difficulties in obtaining information and establishing criteria for estimating the costs of productivity losses [22]. Since 2010 in Poland, this problem has not been investigated sufficiently [2,23], and this stimulated us to conduct a cost analysis of sickness absence with an aim to identify directions in health policy change that will affect productivity growth. This, in turn, will translate into an increase in the level of employment and gross domestic product (GDP).

\section{Objective}

The aim of this study was to estimate indirect costs associated with losses in productivity due to sickness absence among registered workers in Poland.

\section{MATERIAL AND METHODS}

Data on sickness absence in Poland was obtained from the annual reports published by the Social Insurance Institution (SII) (Zakład Ubezpieczeń Społecznych - ZUS) [24]. The analysis was carried out based on the information about the absenteeism of the insured workers in the SII, identified on the basis of medical certificates ZUS ZLA.

The study included 10 groups of diseases as the most common causes of incapacity to work in 2013. The causes of absenteeism were defined on the basis of the International Statistical Classification of Diseases and Related Health Problems 10th Revision (ICD-10) [25]. It included the following groups of diseases: neoplasms ( $\mathrm{C} 00$ D48), mental and behavioral disorders (F00-F99), diseases of the nervous system (G00-G99), diseases of the circulatory system (I00-I99), diseases of the respiratory system (J00-J99), diseases of the digestive system (K00-K93), diseases of the musculoskeletal system and connective tissue (M00-M99), diseases of the genitourinary system (N00-N99), pregnancy, childbirth, and puerperium (O00-O99), injuries, poisoning and certain other effects of exposure to external causes (S00-T98) and total causes (A00-Z99). As one of the causes of absenteeism, we also included absenteeism due to care of a child aged up to 14 years and of another family member.

The costs of lost productivity were estimated using a social approach based on the HCA method [16]. Lost productivity is an assessment of health time lost due to a disease using monetary units. Lost productivity was measured by gross value added (GVA), which is the value of products (goods and services) produced as a result of production activity of national institutional units. Gross value added is the difference between the total revenue of output and the costs of resources used for production and it is expressed in basic prices [26]. Data on GVA and on the number of workers in the national economy by gender in 2013 (as of 31 December) was obtained from Poland's Central Statistical Office (Główny Urząd Statystyczny - GUS). In the analysis, we used data from the year 2013, which was the last year in which data necessary to estimate the indirect costs were available. Gross value added given in Polish currency - Polish zloty (PLN) was converted to euros (EUR) at the exchange rate of the Polish National Bank (1 euro to 4.2 Polish zloty average exchange rate in 2013).

In our analysis, the sick leave was defined as a justified absence from work due to illness. Sickness absence was defined as the sum of sickness absence days, identified on the basis of all medical certificates, which were issued to the insured workers in a given calendar year [24]. However, the number of days off is not an accurate measure of absenteeism. This is due to the fact that the exemptions are issued for a continuous period of time, and inevitably part of this period may fall on non-working days, that is, on Saturdays, Sundays, or holidays. 
In the case of short-term exemptions from 1 to 5 days, it is assumed that in most of the cases the number of days of sick leave is exactly the number of days of absence:

$$
\mathrm{t}_{\text {absence }}=\mathrm{t}_{\text {sick leave }}
$$

In the case of exemptions longer than 5 days, at least one of the days of this period is a day off from work. In such a case, the percentage of working days (and thus, the days of absence) per time period of the sick leave is similar to the percentage of working days in a calendar year. This relationship may be expressed as follows:

$$
\mathrm{t}_{\text {absence }}=\mathrm{t}_{\text {sick leave }} \times \frac{\mathrm{w}}{365}
$$

where:

$\mathrm{w}$ - the number of working days during the year minus the average duration of holiday.

In order to calculate the time of absence based on the aggregate number of days off, a weighted average of 2 cases described above was used:

$$
\mathrm{t}_{\text {absence }}=\alpha \mathrm{t}_{\text {sick leave }}+(1-\alpha) \mathrm{t}_{\text {sick leave }} \times \frac{\mathrm{w}}{365}
$$

where:

coefficient $\alpha$ - the percentage of days off/sick leave for the period from 1 to 5 days in relation to all days of sick leave.

Determination of the value of the coefficient $\alpha$ requires knowledge of the distribution of the number of days of sick leave in the population of all the issued sick leaves, in particular the incidence of sick leaves from 1 to 5 days. Unfortunately, the SII provides only aggregate data on the number of sick leaves at selected intervals of their duration in days $(1-10,11-30,31-35,36-50,51-60,61-$ $90,91-182, \geq 183$ ); therefore, the distribution of the number of days of sick leave was estimated by a theoretical distribution. Distribution parameters were determined in order to obtain the greatest similarity to the empirical data, and parameter optimization criterion was to minimize the compliance of $\mathrm{Chi}^{2}$ test statistics. Using this criterion, the best fit to the empirical data was characterized by a log-normal distribution. Figure 1 shows the SII data on the number of sick leaves and the corresponding expected values calculated on the basis of the obtained distribution. Based on the theoretical distribution of sick leaves duration issued in Poland in 2013, we calculated the total number of sick leaves with a duration of 1-5 days, which accounted for $\alpha=5.98 \%$ of all the days of sick leaves.

Estimated loss of productivity due to absenteeism is the product of the annual GVA per person per day at work and absenteeism time, according to the method described above. The value of the first factor of the product is the quotient of annual GVA and the number of mandays worked out, which is the product of the number of workers and the number of working days in a calendar year, minus the aggregate number of days of absence. The equation allows specification of the lost productivity

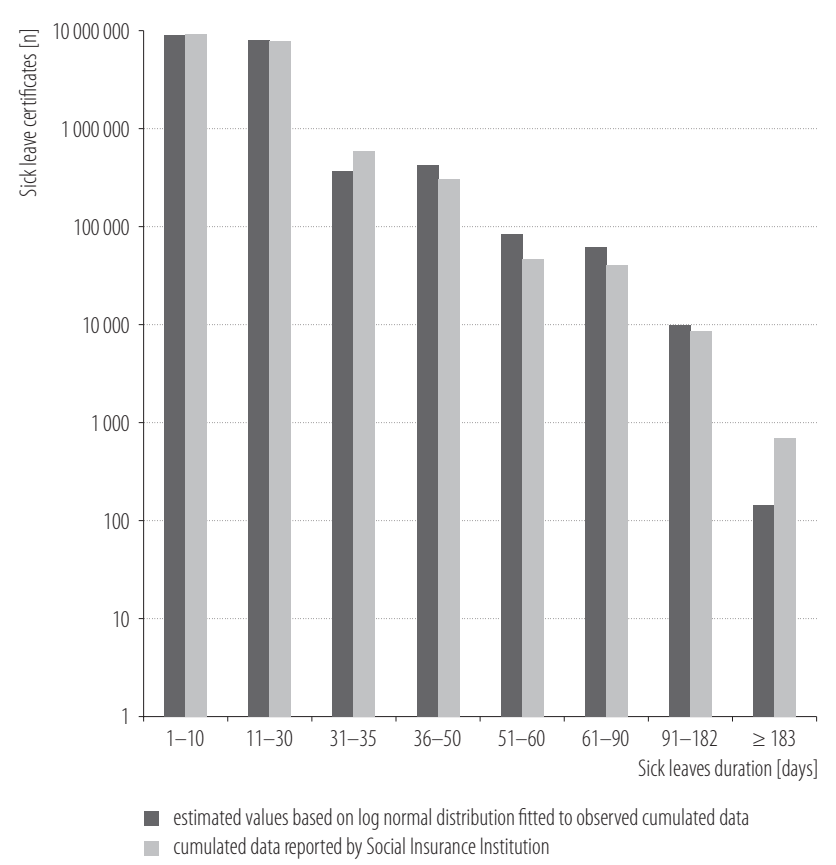

Fig. 1. Sick leaves issued in Poland, 2013, based on the duration of sick leaves reported by the Social Insurance Institution (SII) and estimated based on matching log-normal distribution 
due to absenteeism for a specific reason in a certain demographic group:

$$
\text { loss of productivity }=\frac{\mathrm{GVA}}{\mathrm{n} \times \mathrm{w}-\mathrm{T}} \times \mathrm{t}_{\text {absence }}
$$

where:

GVA - the gross value added,

$\mathrm{n}$ - the total number of people worked,

$\mathrm{w}$ - the number of working days during the year minus the average duration of holidays,

$\mathrm{T}$ - the total number of days of absence in the whole population studied,

$\mathrm{t}_{\text {absence }}$ - the total number of days of absence for specific cause by demographic characteristics (e.g., age and gender), calculated on the basis of the total number of sick leave days in accordance with the abovementioned methodology.

The standard length of holidays in Poland that we adopted in the study was 26 days. Given that teachers, representing $8.5 \%$ in the structure of employment, in 2013 had 35 days of holidays, the calculated average time of holiday was 26.9 days (circa 27 days). This calculation did not take into account the longer period of holiday of a small portion of army personnel, police, judges, prosecutors and social workers due to lack of precise data.
The total number of working days in 2013, after deduction of statutory holidays, was 224 .

\section{RESULTS}

In 2013, among the 7.2 million men and 6.6 million women who worked in Poland, we found a total of 222.6 million days of sickness absence. Estimated value of the loss in productivity due to absenteeism was $4.33 \%$ of GDP, and per each worker in the national economy it amounted to 1460 euro.

Pregnancy, childbirth and puerperium, which are not considered to be diseases, were causing the highest estimated loss of productivity amounting to 2.96 billion euro, i.e., $17.3 \%$ of the total cost of absenteeism. Further causes of loss of productivity were injuries and poisoning (2.4 billion euro), diseases of the respiratory system (2.27 billion euro), and diseases of the musculoskeletal system (2.25 billion euro). In total, these diseases accounted for $40.5 \%$ of the costs. Losses in productivity were also caused by absenteeism associated with caring of family members and amounted to 0.71 billion euro, out of which 0.61 billion euro was the cost of caring of a child up to 14 years (Table 1 ).

The highest costs of loss of productivity were found to be in the age groups of 20-29 years and 30-39 years due to

Table 1. Cost of losses in productivity in all age groups of the total population due to sickness absence in Poland, 2013

\begin{tabular}{|c|c|c|c|c|}
\hline \multirow[b]{2}{*}{ Causes of absence } & \multirow[b]{2}{*}{$\begin{array}{c}\text { Absence } \\
\text { (in thousands) } \\
\text { [days] }\end{array}$} & \multicolumn{3}{|c|}{ Cost of losses } \\
\hline & & $\begin{array}{c}\text { per working } \\
\text { person } \\
\text { [euro] }\end{array}$ & $\begin{array}{l}\text { in productivity } \\
\text { [billion euro] }\end{array}$ & $\begin{array}{c}\text { in relation } \\
\text { to GDP } \\
{[\%]}\end{array}$ \\
\hline \multicolumn{5}{|l|}{ Medical (ICD-10 code) } \\
\hline pregnancy, childbirth, and puerperium (O00-099) & 38.562 & $445^{*}$ & 2.96 & 0.75 \\
\hline $\begin{array}{l}\text { injuries, poisoning, and certain other effects of exposure } \\
\text { to external causes (S00-T98) }\end{array}$ & 31.289 & 173 & 2.40 & 0.61 \\
\hline diseases of the respiratory system (J00-J99) & 29.543 & 163 & 2.27 & 0.58 \\
\hline $\begin{array}{l}\text { diseases of the musculoskeletal system and connective } \\
\text { tissue (M00-M99) }\end{array}$ & 29.252 & 161 & 2.25 & 0.57 \\
\hline diseases of the nervous system (G00-G99) & 18.368 & 101 & 1.41 & 0.36 \\
\hline diseases of the circulatory system (I00-I99) & 12.513 & 69 & 0.96 & 0.24 \\
\hline
\end{tabular}


Table 1. Cost of losses in productivity in all age groups of the total population due to sickness absence in Poland, 2013 - cont.

\begin{tabular}{lcrcc}
\hline & Absence & \multicolumn{3}{c}{ Cost of losses } \\
\cline { 4 - 5 } \multicolumn{1}{c}{ Causes of absence } & $\begin{array}{c}\text { (in thousands) } \\
\text { [days] }\end{array}$ & $\begin{array}{c}\text { per working } \\
\text { person } \\
\text { [euro] }\end{array}$ & $\begin{array}{c}\text { in productivity } \\
\text { [billion euro] }\end{array}$ & $\begin{array}{c}\text { in relation } \\
\text { to GDP } \\
\text { [\%] }\end{array}$ \\
\hline Medical (ICD-10 code) - cont. & & & & \\
mental and behavioral disorders (F00-F99) & 15.618 & 86 & 1.20 & 0.30 \\
diseases of the digestive system (K00-K93) & 8.678 & 48 & 0.67 & 0.17 \\
neoplasms (C00-D48) & 7.474 & 41 & 0.57 & 0.15 \\
diseases of the genitourinary system (N00-N99) & 6.257 & 35 & 0.48 & 0.12 \\
others causes & 15.839 & 87 & 1.21 & 0.30 \\
total (A00-Z99) & 213.393 & 1409 & 16.38 & 4.15 \\
$\quad$ without pregnancy, childbirth, and puerperium (O00-O99) & 174.831 & 964 & 13.42 & 3.40 \\
Care of: & & & & \\
a child up to 14 years old & 7.934 & 44 & 0.61 & 0.15 \\
$\quad$ other family member & 1.293 & 7 & 0.10 & 0.03 \\
Total & 222.620 & 1460 & 17.09 & 4.33 \\
without pregnancy, childbirth, and puerperium (O00-O99) & 184.058 & 1015 & 14.13 & 3.58 \\
\hline
\end{tabular}

ICD-10 - International Statistical Classification of Diseases and Related Health Problems 10th Revision; GDP - gross domestic product.

* The value of losses per working women.

pregnancy, childbirth and puerperium. The highest overall costs of sickness absence by age groups were found in the age group of 30-39 years (5.14 billion euro, after excluding pregnancy, childbirth and puerperium 3.666 billion euro). In addition to pregnancy, childbirth and puerperium in the age group of 30-39 years, the highest burden was due to diseases of the respiratory system ( 0.632 billion euro), injuries and poisoning ( 0.62 billion euro), diseases of the musculoskeletal system ( 0.467 billion euro), and childcare ( 0.404 billion euro).

In the age group of 40-49 years, the largest burden was due to diseases of the musculoskeletal system ( 0.549 billion euro), injuries and poisoning ( 0.527 billion euro), and diseases of the respiratory system $(0.470$ billion euro). Similar reasons were found in the age group of 50-59 years ( 0.806 billion euro, 0.588 billion euro, and 0.526 billion euro, respectively). In the age group of $\geq 60$ years, the highest costs of productivity losses were due to diseases of the musculoskeletal system (0.198 billion euro), diseases of the circulatory system (0.18 billion euros) and injuries and poisoning ( 0.136 billion euro) (Table 2).

We observed disparities in the values of the estimated cost of productivity losses between men and women. In the male population, losses were 7.43 billion euro (i.e., 1023 euro for every working man). In the female population, it was 9.66 billion euro (1451 euro for a working woman), but after excluding the costs of productivity losses due to pregnancy, childbirth and puerperium, it was found that the overall costs of absenteeism in women were lower than in the case of men (6.7 billion euro, i.e., 1006 euro for a working woman).

Among men, $54.4 \%$ of the costs were caused by injuries and poisoning (22.3\%), diseases of the musculoskeletal 
Table 2. Cost of losses in productivity in the total population due to sickness absence by cause and age groups in Poland, 2013

\begin{tabular}{|c|c|c|c|c|c|c|}
\hline \multirow{2}{*}{ Causes of absence } & \multicolumn{6}{|c|}{$\begin{array}{l}\text { Cost of losses in age groups } \\
\text { [billion euro] }\end{array}$} \\
\hline & $\begin{array}{l}<19 \\
\text { years }\end{array}$ & $\begin{array}{l}20-29 \\
\text { years }\end{array}$ & $\begin{array}{l}30-39 \\
\text { years }\end{array}$ & $\begin{array}{l}40-49 \\
\text { years }\end{array}$ & $\begin{array}{l}50-59 \\
\text { years }\end{array}$ & $\begin{array}{l}\geq 60 \\
\text { years }\end{array}$ \\
\hline \multicolumn{7}{|l|}{ Medical (ICD-10 code) } \\
\hline pregnancy, childbirth and puerperium $(\mathrm{O} 00-099)$ & 0.019 & 1.389 & 1.474 & 0.078 & 0.001 & 0.000 \\
\hline $\begin{array}{l}\text { injuries, poisoning and certain other effects of exposure } \\
\text { to external causes (S00-T98) }\end{array}$ & 0.038 & 0.495 & 0.620 & 0.527 & 0.588 & 0.136 \\
\hline diseases of the respiratory system (J00-J99) & 0.048 & 0.463 & 0.632 & 0.470 & 0.526 & 0.128 \\
\hline $\begin{array}{l}\text { diseases of the musculoskeletal system and connective } \\
\text { tissue (M00-M99) }\end{array}$ & 0.008 & 0.218 & 0.467 & 0.549 & 0.806 & 0.198 \\
\hline diseases of the nervous system (G00-G99) & 0.004 & 0.150 & 0.338 & 0.365 & 0.452 & 0.102 \\
\hline diseases of the circulatory system (I00-I99) & 0.001 & 0.040 & 0.109 & 0.196 & 0.434 & 0.180 \\
\hline mental and behavioral disorders (F00-F99) & 0.002 & 0.168 & 0.376 & 0.313 & 0.293 & 0.046 \\
\hline diseases of the digestive system (K00-K93) & 0.008 & 0.109 & 0.162 & 0.150 & 0.186 & 0.051 \\
\hline neoplasms (C00-D48) & 0.001 & 0.029 & 0.077 & 0.147 & 0.237 & 0.083 \\
\hline diseases of the genitourinary system (N00-N99) & 0.003 & 0.075 & 0.132 & 0.124 & 0.123 & 0.023 \\
\hline others causes & 0.015 & 0.227 & 0.317 & 0.250 & 0.317 & 0.089 \\
\hline total (A00-Z99) & 0.147 & 3.363 & 4.704 & 3.169 & 3.963 & 1.036 \\
\hline without pregnancy, childbirth, and puerperium (O00-099) & 0.128 & 1.974 & 3.230 & 3.091 & 3.962 & 1.036 \\
\hline \multicolumn{7}{|l|}{ Care of: } \\
\hline a child up to 14 years old & 0.001 & 0.090 & 0.404 & 0.104 & 0.009 & 0.001 \\
\hline other family member & 0.000 & 0.013 & 0.033 & 0.020 & 0.028 & 0.006 \\
\hline Total & 0.148 & 3.466 & 5.140 & 3.294 & 4.000 & 1.042 \\
\hline without pregnancy, childbirth, and puerperium (O00-O99) & 0.129 & 2.077 & 3.666 & 3.216 & 3.999 & 1.042 \\
\hline
\end{tabular}

ICD-10 - International Statistical Classification of Diseases and Related Health Problems 10th Revision.

system $(17 \%)$ and diseases of the respiratory system $(15.1 \%)$. Similarly, in the structure of loss of productivity among women (excluding costs caused by pregnancy, childbirth and puerperium), these diseases accounted for $43 \%$ of the costs $(11.2 \%, 14.6 \%, 17.2 \%$, respectively). While taking into account the structure of loss including pregnancy, childbirth and puerperium, the problem constituted $30.6 \%$ of the costs; diseases of the respiratory system: $11.9 \%$ and diseases of the musculoskeletal system: $10.1 \%$, and these causes together accounted for $52.6 \%$ of the costs. Comparing the costs of productivity losses in men and women, higher losses in the productivity of women in addition to pregnancy, childbirth and puerperium were caused by mental and behavioral disorders, diseases of the genitourinary system and neoplasms. In men, when compared to women, we observed higher losses due to injuries and poisoning, and diseases of musculoskeletal, nervous, circulatory and digestive systems. In both sexes, similar losses were caused by the diseases of the respiratory system (Table 3). 


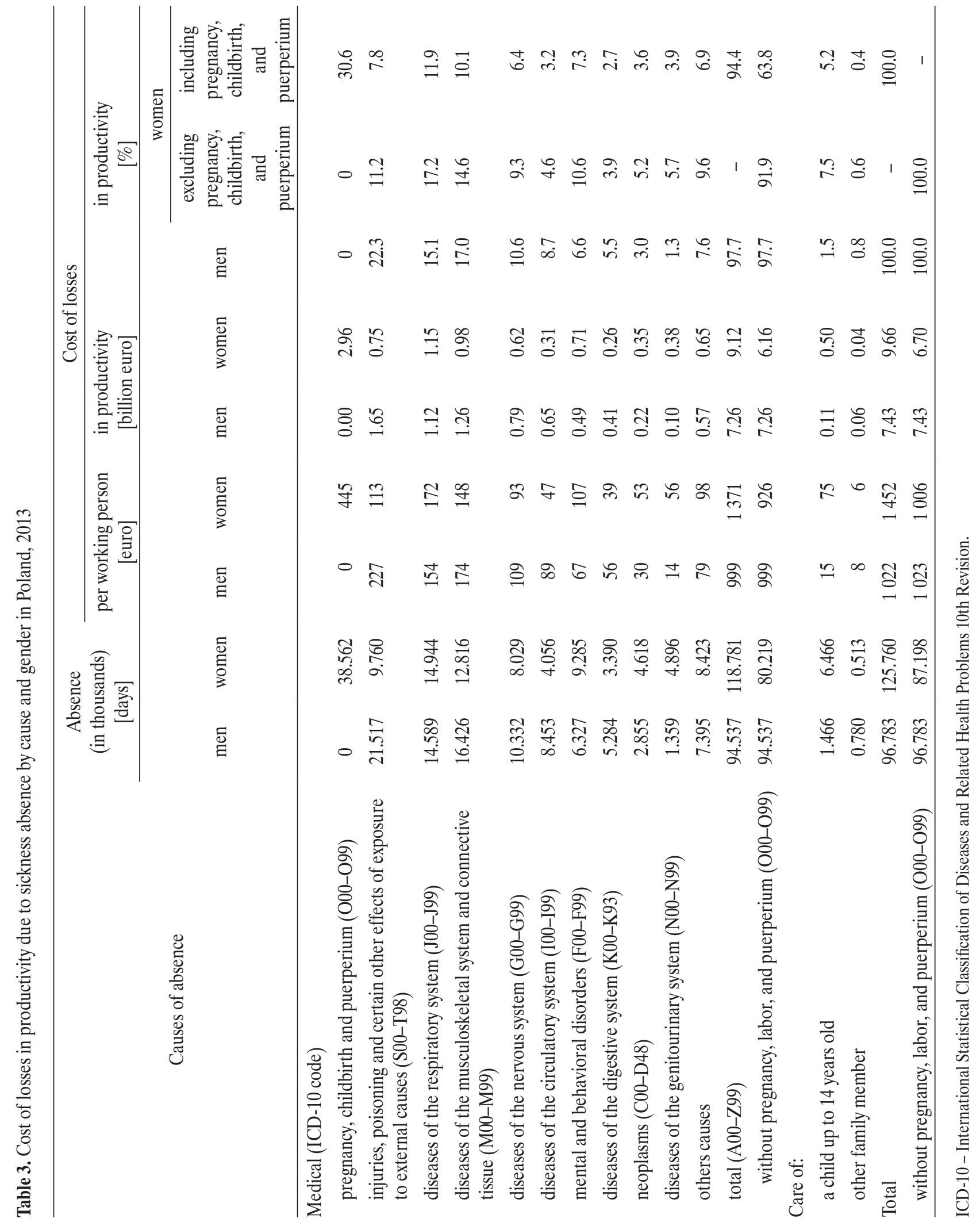




\section{DISCUSSION}

The total indirect costs of absenteeism in Poland in 2013 amounted to 17.09 billion euro, which corresponds to the loss of 1460 euro for each worker. General estimated cost of uncompleted work in the amount of $4.33 \%$ of GDP shows large-scale losses to society. A significant proportion of the total cost of lost productivity in 2013, i.e., $57.7 \%$, was due to sickness absence caused by pregnancy, childbirth and puerperium (17.3\%), injuries and poisoning (14\%), diseases of the respiratory system (13.2\%), and diseases of the musculoskeletal system (13.2\%). Similar causes of absenteeism have been demonstrated in some other European countries [22].

Besides the main causes of sickness absence, Eurofound emphasizes that comparison between European countries is problematic due to the lack of data about the level of absenteeism in some countries (e.g., France and Romania) or fragmentation of the existing data. An additional difficulty in comparing data internationally is the existence of different definitions of sickness absence (e.g., the length of absence and taking into account family care), which may reduce the reliability of the calculations carried out and the results obtained in terms of comparisons. The consequence of this approach is the lack of standardized measurement tools, and in the longer term, inability to compare results from different countries. The estimated cost of absenteeism in Poland at the level of $0.29 \%$ of GDP including sick benefits paid by the Social Insurance Institution and on the other hand, the costs of absenteeism in Estonia amounting to 5.4\% of GDP including benefits for sickness, nursing, occupational injury and maternity leave may be used as the evidence on this issue. It is evident that even on the availability of data for measurement of absenteeism, a wide margin of error occurs, and international comparisons of data become risky. However, Eurofound study indicates that a reasonable estimate of cost is about $2.5 \%$ of GDP [22].

The high cost of absenteeism in Poland as found in this study (4.33\% of GDP) may indicate a low efficiency of the health care system and institutions dealing with the protection of health in the workplace. Studies [27] also indicate that the overall level of unmet health needs in terms of diagnosis and treatment in Poland was higher in comparison with the developed European countries. The biggest limitation in the access to health care concerns people in the lowest income quartile, among who the level of unmet needs was significantly higher.

In contrast to the vast majority of European systems, in Poland there is no single occupational health service, instead, there are 2 independent services, the in-house based work safety and hygiene service, and the external occupational medicine service, with little coordination between the 2 [28]. Other authors [29] have also described weaknesses in the system such as preventive care for workers involving lack of respect for legal standards by workers and representatives of occupational health services. Nearly $50 \%$ of the workers violate provisions relating to the initial and periodic medical examinations, as a result of which, hundreds of thousands of workers do not undergo obligatory medical examinations. It also shows the lack of cooperation between medicine centers and workers and their organizations or primary care physicians [29]. In addition, there are also problems with the lack of a coordination mechanism that would ensure the earliest return to work after medical rehabilitation [28].

This survey indicated that pregnancy, childbirth and puerperium, although concerned only women, in the general structure of the causes of absenteeism regardless of sex are superior to other diseases and health problems among workers. On the one hand, these are the reasons that brought not only the greatest losses in productivity ( $0.75 \%$ of GDP, i.e., 2.96 billion euro) but also benefits that should be noted as the benefits of full-term pregnancies, so it is difficult to consider these costs only as financial losses (rather, in fact, it should be considered as long-time social investments). Since 2008, pregnancy, childbirth and puerperium have been the main reasons 
for issuing certificates of incapacity to work, and the most common in this group of causes of absenteeism was "maternal care of other conditions predominantly related with pregnancy" [24].

Studies conducted by Marcinkiewicz and Hanke [30] among gynecologists have indicated that the decision to issue a certificate of incapacity to work temporarily was determined by, besides the state of pregnancy, the risk and inconvenience related to working conditions. Among the reasons emphasized by gynecologists there were: risky pregnancy and the need to reduce complications associated with workplace and eliminate the risks associated with work. Issuing certificates of incapacity to work in a poor working environment for pregnant women can protect the fetus from preterm delivery and low birth weight, which lead to infant mortality.

The Polish mother-child cohort study has shown that none of the 954 women surveyed was transferred to another job while pregnant [31], despite the fact that legislation emphasizes the need to transfer pregnant women to jobs where they will not be exposed to potentially harmful or hazardous factors [32] and to adjust working conditions in order to eliminate threats to the health or safety of pregnant women [33]. These results [30,31] indicate the need to increase awareness among workers concerning the risks that a pregnant woman and her fetus face in the workplace. Measures aimed at creating working conditions that are safe for pregnant women may reduce the cost of lost productivity due to absenteeism of pregnant women, as well as high financial burden for the payer of insurance benefits.

Research conducted by Marcinkiewicz and Hanke [30] has also disclosed very little involvement of occupational health services and workers in activities related to preventive care over the working pregnant women, pointing to poor cooperation between medical doctors and gynecologists working in the field of exchange of information on the health status and working conditions of pregnant women. The authors emphasize the need to develop medical standards concerning preventive care of working pregnant women and raising awareness of occupational medicine physicians and obstetricians-gynecologists in the field of occupational health hazards that concern pregnant women. These activities could help improve the effectiveness of preventive care of working pregnant women, which, in turn, may be associated with a reduction in the scale of use of sick leave without a justified cause [30].

In the United Kingdom, sickness absence due to pregnancy is $3 \%$, which is 6 times lower in comparison to Poland. This smallness in the scale of sickness absence is the result of a consistent and intersectoral health policy pursued for a decade by the British government, including, among others, education of workers, preventive health care, optimizing access to a doctor, improved working conditions, systematic sealing of the settlement system of exemptions and benefits, as well as financial incentives for workers and employers [34]. Major effort in preventive care for working pregnant women, besides creating appropriate working conditions, should also be focused on the education concerning performance of duties with regard to the scope and frequency of household activities similar to professional tasks (e.g., work with a computer) [35].

The current study shows that the value of the cost of productivity losses due to pregnancy, childbirth and puerperium was highest among persons aged 30-39 years. This may be explained by the increase in the average age of mothers [36] resulting from deferring decisions about motherhood, longer duration of education and focus on a career. It should be also noted that the later age of ongoing pregnancy may result in a higher risk of complications during pregnancy [37], which entails an increase in absenteeism. Apart from the costs of pregnancy, childbirth and puerperium, the results obtained for the cost of care of a child aged up to 14 years also draw attention, Such costs reached the highest value in the age group 30-39 years. 
High cost of absenteeism after 40 years of age was due to musculoskeletal diseases, and the results obtained were consistent with other studies [38]. The costs of loss of productivity due to these diseases are associated with the limits of efficiency, leading to difficulties in everyday functioning and in the professional sphere. It should be also noted that musculoskeletal diseases, next to circulatory system diseases and neoplasms, are chronic diseases caused by irreversible pathological changes and need rehabilitation or long period of supervision, observation or care [39].

In the current study we found that in the group of employees with diseases (musculoskeletal, circulatory system, neoplasms) costs of productivity losses in the oldest age group ( $\geq 60$ years) were relatively low, which could be due to early withdrawal from the labor market because of the inability to perform professional activities. This result was confirmed by the SII study, which has indicated that the average age at which there was a complete inability to work due to musculoskeletal, circulatory diseases and neoplasms was, respectively, 53.2 years, 54.8 years, and 53.3 years [40]. One of the main risk factors for the development and progression of these health problems is overweight and obesity. Studies conducted in the Canadian population have shown that obesity is an independent risk factor for reduced productivity at work, absenteeism and presenteeism [41]. An optimistic fact in this situation is the fact that these are modifiable risk factors, which allows building programs that may contribute to improving the health status of the working population.

High cost of productivity loss due to absenteeism caused by civilization diseases requires taking intensive systemic actions in the field of health promotion, disease prevention and early diagnosis to enable appropriate treatment. In the case of musculoskeletal diseases, examination of the Spanish population has confirmed that the investment in the health of working people brings a rapid and significant return, as measured by the reduction in the average time spent on sick leave from 41 days to 26 days [42]. Also, other studies on diseases of the circulatory system [43] and neoplasms [44] indicate a high economic cost of absenteeism related to the underlying diseases and justify taking action on the early detection and prevention of these diseases in order to reduce the cost of insurance benefits.

Diseases of the circulatory system and neoplasms are responsible for over $70 \%$ of deaths in Polish population [36], and in the cost structure of productivity losses they occupied distant 6 and 9 positions (respectively $5.6 \%$ and $3.3 \%$ of the total costs). These smaller productivity losses compared to other diseases are related to shifting to annuity-generating expenses in the social security system. Among the first-time decisions for annuity purposes, diseases of the circulatory system and neoplasms were $21.3 \%$ and $22.3 \%$ [40].

Low level of education is among the factors that influence reduction in the level of productivity and efficiency and the level of sickness absence. In addition, people with low education often present harmful lifestyle (e.g., unhealthy diet, smoking and alcohol consumption), which further increases the likelihood of sickness absence in this social group and can also lead to premature deaths $[5,45,46]$. This problem could be rectified by intense actions such as providing workers with access to early diagnosis and health services and promoting health in the workplace, which could potentially reduce absenteeism and costs associated with it.

An important result of this work is finding of disparities between the estimated cost of the loss of productivity between men and women. This phenomenon results from the inequalities in health, which may be explained by differences in hormonal, metabolic and genetic etiology, and influencing the development of diseases. In addition, the existing gender segregation in employment makes women and men perform in different conditions, which is associated with differences in health risks $[8,47]$. Gender gap can also increase work-related stress leading to health problems. 
The causes of absenteeism, which in the present study generated higher losses in women (i.e., mental and behavioral disorders, diseases of the genitourinary system, and neoplasms), were assigned as specific female diseases [48,49]. Other authors also point out greater burden of mental health problems in women due to a greater exposure to job insecurity, lower wages, worse conditions in the psychosocial work environment and stress resulting from double burden responsibilities (work and care of the family) [7]. Among men, higher losses were observed due to injuries and poisoning, and diseases of musculoskeletal, nervous, circulatory and digestive systems. Working in a construction industry is associated with dangers in the work environment, high physical demands and a greater susceptibility to accidents, back strain and nerve root and plexus disorders. Blue-collar workers are also often exposed to hypertension, obesity and overweight [7,50].

Literature indicates that absenteeism in most European Union countries is higher in women due to pregnancy and double burden duties [8]. However, it should be noted that the results of the present study indicate that after excluding pregnancy, childbirth and puerperium, the overall costs were higher in men compared to women, which may be due to a significantly higher severity of work referred to energy expenditure among men associated with adverse health consequences [51]. The estimated costs of individual groups of diseases as the cause of absenteeism may be a tool for determining health priorities and planning activities in the field of health in the workplace, of course with taking into account the level of education [20].

Conducting studies on the cost of the disease is extremely important in Poland and other countries of the CentralEastern Europe, where a lower level of prosperity and weaker conditions of the health care system after a period of political change often do not respond to existing health needs of the society [52]. The problems of weak health conditions act as barriers to reduce the economic gap compared to richer countries. Currently, overcoming this problem is difficult due to demographic changes resulting in reduction of the working-age population and a simultaneous increase in the beyond retirement age population. European Commission has emphasized that there will be a decline in economic growth and rise in health care costs [53]. These projections emphasize that efforts to reduce the risk of early withdrawal of employees from the labor market due to illness have to be intensified. This can be achieved by implementing health-related programs in the working-age population. A recent systematic review of intervention studies on workplace health promotion for older workers has shown that well planned programs may improve health and productivity of workers [54-56].

\section{Limitations and strengths}

Despite using a wide range of available data, the study has some limitations. Indirect costs of illness were assessed by a common approach HCA, but as a standard methodology for data interpretation is lacking, comparison of the results with other studies should be conducted with caution. The limitation of this study is also due to the difficulties in estimating the number of days of annual leave entitlement by seniority or professional groups. In Poland, workers having less than 10 years of work experience are entitled to 20 days of vacation, but the number of employees having less than 10 years of work experience (who are entitled to 20 days of vacation) is smaller compared to workers with more than 10 years of experience who are entitled to 26 days of vacation [32]. In addition, some professional groups (e.g., military, police, judges, prosecutors, and social workers) are entitled to a significantly longer vacation. Unfortunately, an accurate estimation of the average vacation time, taking into account this specific permission to leave, was difficult due to the lack of access to relevant information. However, their combined share in the labor market is approximately $1.5 \%$, which has little impact on the estimated parameter. 
Costs of informal care of the family, which was not included due to limitations in the access to the source data, constitutes an unexplored problem. The underestimation of costs could be attributed to work by minors, black economy workers and persons who work on a contract basis but are not listed in the system of SII insurance. Instead, the overestimation of the cost may be associated with sickness absence of the unemployed persons included in the system SII. These people, due to their participation in educational and therapeutic programs, were entitled to receive medical certificates, but they did not generate wages and profits for the economy [24,57]. The study assumes equal productivity of all workers, which is a rather simplistic interpretation of costs converted to person. In addition, it should be also noted that the sick leave is a measure of morbidity, but in the case of sickness in pregnant women, results should be interpreted with caution. In the case of pregnant women issuing certificates of temporary incapacity to work is often not related to their but to the risk occurring in the work environment.

Nevertheless, our study is the first to estimate the indirect costs of lost productivity due to sickness absence in Polish population. The study used complete data on sickness absence of people in the SII system, the insurer of about $84 \%$ of the population [24], which makes the study reliable. We estimated the value of the results by GVA, which is a better measure of assessing indirect costs of productivity losses in comparison to the GDP measure. Gross value added takes into account the increase in the value of goods generated by human and financial capital and leaves the taxes and subsidies than those arising from the work itself, magnifying the value of production.

An important advantage of this work is estimation of the cost of child care and other family members, which are rarely included in research on costs of sickness absence. The calculations tried to eliminate the revaluation results, related to the fact that the duration of the exemption periods recorded by the SII also include days off from work. A strong argument for conducting this study was to evaluate the indirect costs of absenteeism from a societal perspective that can be used to make optimal decisions regarding reduction of diseases, which may contribute to increased productivity and professional competitiveness of the economy [18,21]. Estimation of indirect costs of absenteeism can be a tool for planning preventive programs aimed at gains in workers' health.

\section{CONCLUSIONS}

Diseases and health problems of economically active people lead to significant losses in productivity, amounting to $4.33 \%$ of GDP. Estimating indirect costs of particular diseases can help health policy makers set priorities aimed at reducing the risk of early withdrawal from the labor market. Improvement and further development of effective strategies for prevention of complications of pregnancy and diseases and health problems including sex, age and education in the workplace are necessary. The social impact, in terms of loss of productivity, requires effective strategies aimed at treatment, rehabilitation and prevention in the working population. Prevention of diseases and health problems also requires improvement of system solutions in the field of occupational health and realization of cooperation between institutions involved in work environment protection. These measures may contribute to improvement in the quality of human capital and the increase in the socioeconomic development.

\section{REFERENCES}

1. Kivimäki M, Head J, Ferrie JE, Shipley MJ, Vahtera J, Marmot MG. Sickness absence as a global measure of health: Evidence from mortality in the Whitehall II prospective cohort study. BMJ. 2003;327(7411):364, https://doi.org/10.1136/bmj. 327.7411.364.

2. Szubert Z. [Sickness absence in Poland after socio-economic transformation]. Med Pr. 2014;65(1):73-84, https://doi.org/ 10.13075/mp.5893.2014.003. Polish. 
3. [The act of 25 June 1999 on cash social insurance benefits in respect of sickness and maternity, consolidated text. J Laws 2016, No. 0, item 372]. Polish.

4. Magnavita N, Garbarino S. Is absence related to work stress? A repeated cross-sectional study on a special police force. Am J Ind Med. 2013;56(7):765-75, https://doi.org/10.1002/ ajim.22155.

5. Robroek S, van Lenthe F, Burdorf A. The role of lifestyle, health, and work in educational inequalities in sick leave and productivity loss at work. Int Arch Occup Environ Health. 2013;86(6):619-27, https://doi.org/10.1007/s00420-012-0793-1.

6. Piha K, Laaksonen M, Martikainen P, Rahkonen O, Lahelma E. Interrelationship between education, occupational class, income and sickness absence. Eur J Public Health. 2010;20(3):276-80, https://doi.org/10.1093/eurpub/ckp162.

7. Campos-Serna J, Ronda-Pérez E, Artazcoz L, Moen BE, Benavides FG. Gender inequalities in occupational health related to the unequal distribution of working and employment conditions: A systematic review. Int J Equity Health. 2013;12:57, https://doi.org/10.1186/1475-9276-12-57.

8. Ardito C, d'Errico A, Leombruni R, Pacelli L. Health and well-being at work: A report based on the fifth European Working Conditions. Dublin: Eurofound; 2012.

9. Parent-Thirion A, Macias E, Hurley J, Vermeylen G. Fourth European Working Conditions Survey. Dublin: Eurofound; 2007.

10. Eurofound [Internet]. Dublin: Eurofound; 2016 [cited 2016 May 25]. Sixth European Working Conditions Survey 2015. Available from: http://www.eurofound.europa.eu/surveys/ data-visualisation/sixth-european-working-conditions-survey-2015.

11. Hermanowski T, editor. [Estimating the social costs of the disease and the impact on health on the labor force and productivity]. Warszawa: Wolters Kluwer Business; 2013. Polish.

12. Wrona W, Hermanowski T, Golicki D, Jakubczyk M, Macioch $\mathrm{T}$, Goszczyńska $\mathrm{K}$, et al. [Cost of lost productivity in pharmacoeconomics analysis Part I. A systematic review of the literature]. Przegl Epidemiol. 2011;65(1):147-52. Polish.
13. Krol M, Papenburg J, Koopmanschap M, Brouwer W. Do productivity costs matter? The impact of including productivity costs on the incremental costs of interventions targeted at depressive disorders. Pharmacoeconomics. 2011;29(7): 601-19, https://doi.org/10.2165/11539970-000000000-00000.

14. Michael MD, Bálint A, Lovász BD, Gulácsi L, Strbák B, Golovics PA, et al. Work disability and productivity loss in patients with inflammatory bowel diseases in Hungary in the era of biologics. J Health Econ. 2014;15 Suppl 1:S121-8, https://doi.org/10.1007/s10198-014-0603-7.

15. Hodgson T, Meiners M. Cost-of-illness methodology: A guide to current practices and procedures. Milbank Mem Fund Q Health Soc. 1982;60(3):429-62, https://doi.org/10.2307/ 3349801.

16. Koopmanschap M, Burdorf A, Jacob K, Meerding WJ, Brouwer W, Sverens H. Measuring productivity changes in economic evaluation: Setting the agenda. Pharmacoeconomics. 2005;23(1):47-54, https://doi.org/10.2165/00019053200523010-00004.

17. Clabaugh G, Ward MM. Cost-of-illness studies in the United States: A systematic review of methodologies used for direct cost. Value Health. 2008;11(1):13-21, https://doi.org/ 10.1111/j.1524-4733.2007.00210.x.

18. Zhang W, Bansback N, Anis A. Measuring and valuing productivity loss due to poor health: A critical review. Soc Sci Med. 2011;72(2):185-92, https://doi.org/10.1016/j.socscimed.2010.10.026.

19. Mattke S, Balakrishnan A, Bergamo G, Newberry SJ. A review of methods to measure health-related productivity loss. Am J Manag Care. 2007;13(4):211-7.

20. Mitchell R, Bates P. Measuring health-related productivity loss. Popul Health Manag. 2011;14(2):93-8, https://doi.org/ 10.1089/pop.2010.0014.

21. Krol M, Brouwer WB, Severens JL, Kaper J, Evers SM. Productivity cost calculations in health economic evaluations: Correcting for compensation mechanisms and multiplier effects. Soc Sci Med. 2012;75(11):1981-8, https://doi.org/ 10.1016/j.socscimed.2012.07.012. 
22. Eurofound [Internet]. Dublin: Eurofound; 2016 [cited 2016 May 30]. EurWORK: European Observatory of Working Life. Absences from work. Available from: http://www.eurofound.europa.eu/observatories/eurwork/comparative-information/absence-from-work.

23. Macioch T, Hermanowski T. The indirect costs of cancerrelated absenteeism in the workplace in Poland. J Occup Environ Med. 2011;53(12):1472-7, https://doi.org/10.1097/ JOM.0b013e3182398dc7.

24. Karczewicz Z, Sikora A. [Sick leave in 2013]. Warszawa: Zakład Ubezpieczeń Społecznych; 2014. Polish.

25. World Health Organization [Internet]. International Statistical Classification of Diseases and Related Health Problems 10th Revision (ICD-10). Version for 2016. [cited 2016 Nov 29]. Available from: http://apps.who.int/classifications/ icd10/browse/2016/en.

26. [Central Statistical Office. Gross Domestic Product, regional account in 2013]. Katowice: The Office; 2015. Polish.

27. Wojtyniak B, Goryński P, Moskalewicz B, editors. [Health situation of the Polish population and its determinants]. Warszawa: Narodowy Instytut Zdrowia Publicznego Państwowy Zakład Higieny; 2012. Polish.

28. Dobras M, Sakowski P, Fries-Tersch E. Safer and healthier work at any age - Country Inventory: Poland [Internet]. Bilbao: European Agency for Safety and Health at Work; 2016 [cited 2016 Oct 28]. Available from: https://www.osha. europa.eu/pl/tools-and-publications/publications/safer-andhealthier-work-any-age-country-inventory-poland/view.

29. Kopias JA. [Realities of the prophylactic health care of workers in Poland]. Med Pr. 2015;66(6):815-25, https://doi. org/10.13075/mp.5893.00229. Polish.

30. Marcinkiewicz A, Hanke W. [Preventive care of pregnant employees. Is there a need to set rules of cooperation between occupational physicians and gynecologist-obstetricians?]. Med Pr. 2012;63(5):591-8. Polish.

31. Polańska K, Jurewicz J, Marcinkiewicz A, MakowiecDąbrowska T, Hanke W. [Occupational activity during pregnancy based on the Polish Mother and Child Cohort
Study]. Med Pr. 2014;65(1):65-72, https://doi.org/10.13075/ mp.5893.2014.004. Polish.

32. [The Act of 26 June 1974 concerning the Labour Code. J Laws 1974, No. 24, item 141 with subsequent amendments]. Polish.

33. [Regulation of the Council of Ministers of 10 September 1996 on the work that is extremely burdensome or harmful to women's health. J laws 1986, No. 114, item 545]. Polish.

34. Gierczyński J. [Sick leave working as a problem of insurance - Compare the situation in Poland and in the UK]. Wiad Ubezpieczeniowe. 2014;3:57-70. Polish.

35. Marcinkiewicz A, Wężyk A, Muszyński P, Polańska K, Makowiec-Dąbrowska T, Wiszniewska M, et al. [Good practice in occupational health services - The influence of hazardous conditions and nuisance coexisting in the work environment and at home on course and outcome of pregnancy]. Med Pr. 2015;66(5):713-24, https://doi.org/10.13075/ mp.5893.00201. Polish.

36. [Central Statistical Office. Demographic Yearbook of Poland 2015]. Warszawa: The Office; 2015. Polish.

37. Ariansen AM, Mykletun A. Does postponement of first pregnancy increase gender differences in sickness absence? A register based analysis of Norwegian employees in 19932007. PLoS One. 2014;9(3):e93006, https://doi.org/10.1371/ journal.pone.0093006.

38. Laires P, Canhão H, Gouveia M. Indirect costs associated with early exit from work attributable to rheumatic diseases. J Public Health. 2015;25(4):677-82, https://doi.org/10.1093/ eurpub/cku241.

39. Pan American Health Organization [Internet]. Washington: The Organization [cited 2016 Jul 8]. Chronic diseases. Available from: http://www.paho.org/hq/index.php?option=com topics\&view $=$ article $\& \mathrm{id}=217 \&$ Itemid $=40875 \&$ lang $=$ en .

40. [Social Insurance Institution. Opinion of the medical board of the of Social Insurance Institution (ZUS) concerning inability to work, 2013]. Warszawa: The Institution; 2014. Polish.

41. Sanchez Bustillos A, Vargas KG 3rd, Gomero-Cuadra R. Work productivity among adults with varied body mass 
index: Results from a Canadian population-based survey. J Epidemiol Glob Health. 2015;5(2):191-9, https://doi. org/10.1016/j.jegh.2014.08.001.

42. Abásolo L, Blanco M, Bachiller J, Candelas G, Collado P, Lajas C, et al. A health system program to reduce work disability related to musculoskeletal disorders. Ann Intern Med. 2005;143(6):404-14, https://doi.org/10.7326/0003-4819143-6-200509200-00005.

43. Song X, Quek RG, Gandra SR, Cappell KA, Fowler R, Cong Z. Productivity loss and indirect costs associated with cardiovascular events and related clinical procedures. BMC Health Serv Res. 2015;15:245, https://doi.org/10.1186/ s12913-015-0925-x.

44. Tangka FK, Trogdon JG, Nwaise I, Ekwueme DU, Guy GP Jr, Orenstein D. State-level estimates of cancer-related absenteeism costs. J Occup Environ Med. 2013;55(9):1015-20, https://doi.org/10.1097/JOM.0b013e3182a2a467.

45. Pikala M, Bryła M, Marcinkowski J, Maniecka-Bryła I. [Socioeconomic determinants of mortality in Poland]. Hygeia Public Health. 2013;48(1):35-9. Polish.

46. Maniecka-Bryła I, Bryła M, Bryła P, Pikala M. The burden of premature mortality in Poland analyzed with the use standard expected years of life lost. BMC Public Health. 2015;15:101, https://doi.org/10.1186/s12889-015-1487-x.

47. Johnson J, Greaves L, Repta R. Better science with sex and gender: Facilitating the use of a sex and gender-based analysis in health research. Int J Equity Health. 2009;8:14, https:// doi.org/10.1186/1475-9276-8-14.

48. Łojko D, Czajkowska A, Suwalska A, Pałys W, Jaracz K, Górna $\mathrm{K}$, et al. Symptoms of depression among adults in rural areas of western Poland. Ann Agric Environ Med. 2015;22(1):152-5, https://doi.org/10.5604/12321966.1141386.
49. Magnavita N. Is there a gender gap in Italian radiology? A cross-sectional study. Eur J Radiol. 2013;82(9):e502-7, https://doi.org/10.1016/j.ejrad.2013.04.007.

50. Piha K, Laaksonen M, Martikainen P, Rahkonen O, Lahelma E. Socio-economic and occupational determinants of work injury absence. J Public Health. 2013;23(4):693-8, https://doi.org/10.1093/eurpub/cks162.

51. Kravitz L, Robergs RA, Heyward VH, Wagner DR, Powers K. Exercise mode and gender comparisons of energy expenditure at self-selected intensities. Med Sci Sports Exerc. 1997;29(8):1028-35.

52. Zatoński W, editor. Closing the health gap in European Union. Warszawa: Cancer Epidemiology and Prevention Division, Maria Skłodowska-Curie Memorial Cancer Center and Institute of Oncology; 2008.

53. European Commission, Directorate-General for Economic and Financial Affairs. The 2012 Ageing Report: Economic and budgetary projections for the EU27 Member States (2010-60). Eur Economy. 2012;2:1-472, https://doi.org/10.2765/19991.

54. Kleszczewska E, Kleszczewski T. [Impact of pro-health programs on the concept of future enterprises]. Probl Hig Epidemiol. 2012;93(4):667-72. Polish.

55. Alexopoulos EC, Zisi M, Manola G, Darviri C. Short-term effects of a randomized controlled worksite relaxation intervention in Greece. Ann Agric Environ Med. 2014;21(2): 382-7, https://doi.org/10.5604/1232-1966.1108609.

56. Poscia A, Moscato U, la Milia DI, Milovanovic S, Stojanovic J, Borghini A, et al. Workplace health promotion for older workers: A systematic literature review. BMC Health Serv Res. 2016;16 Suppl 5:329, https://doi.org/10.1186/s12913-016-1518-z. 57. [The Act of 13 June 2003 on social employment. J laws 2003, No. 122, item 1143 with subsequent amendments]. Polish.

This work is available in Open Access model and licensed under a Creative Commons Attribution-NonCommercial 3.0 Poland License - http://creativecommons.org/ licenses/by-nc/3.0/pl/deed.en. 